\title{
Metode Pembobotan Jarak dengan Koefisien Variasi untuk Mengatasi Kelemahan Euclidean Distance pada Algoritma $k$-Nearest Neighbor
}

\author{
Agustiyar $^{1 *}$, Romi Satria Wahono ${ }^{2),}$ Catur Supriyanto ${ }^{3)}$ \\ 1) LLDIKTI Wilayah VI Semarang \\ 2,3) Teknik Informatika, Universitas Dian Nuswantoro Semarang \\ 1)agustiyar001@gmail.com, ${ }^{2)}$ romi@romisatriawahono.net, ${ }^{3)}$ caturs@ research.dinus.ac.id
}

\begin{abstract}
$k$-Nearest Neighbor ( $k$-NN) is one of the classification algorithms which becomes top 10 in data mining. $k$-NN is simple and easy to apply. However, the classification results are greatly influenced by the scale of the data input. All of its attributes are considered equally important by Euclidean distance, but inappropriate with the relevance of each attribute. Thus, it makes classification results decreased. Some of the attributes are more or less relevance or, in fact, irrelevant in determining the classification results. To overcome the disadvantage of k-NN, Zolghadri, Parvinnia, and John proposed Weighted Distance Nearest Neighbor (WDNN) having the performance better than $k$-NN. However, when the result is $k>1$, the performance decrease. Gou proposed Dual Distance Weighted Voting k-Nearest Neighbor (DWKNN) having the performance better than k-NN. However, DWKNN focused in determining label of classification result by weighted voting. It applied Euclidean distance without attribute weighting. This might cause all attribute considered equally important by Euclidean distance, but inappropriate with the relevance of each attribute, which make classification results decreased. This research proposed Coefficient of Variation Weighting k-Nearest Neighbor (CVWKNN) integrating with MinMax normalization and weighted Euclidean distance. Seven public datasets from UCI Machine Learning Repository were used in this research. The results of Friedman test and Nemenyi post hoc test for accuracy showed CVWKNN had better performance and significantly different compared to $k$-NN algorithm.
\end{abstract}

Keywords: $k$-NN, attribute weighting, weighted Euclidean distance, MinMax normalization

\section{PENDAHULUAN}

$k$-NN pertama kali diperkenalkan pada awal tahun 1950an (Jiawei et al. 2012). $k$-NN adalah sebuah algoritma klasifikasi yang mengklasifikasikan data baru berdasarkan kedekatannya (Han and Kamber 2011). Cara kerja $k$-NN dengan mencari jarak terdekat data uji terhadap $k$ tetangga terdekat data latih (Christian Gratia Nugroho, Didik Nugroho 2015) (Raymundus, YS, and Siswanti 2013). Kedekatan antar data diukur dengan fungsi jarak, fungsi jarak yang paling sering digunakan adalah Euclidean distance (Schenatto et al. 2017) (Akhil, Deekshatulu, and Chandra 2013). $k$-NN memiliki kelebihan, yaitu sederhana dan hasilnya mudah dijelaskan (Hocke and Martinetz 2015), mudah dimengerti untuk klasifikasi dan regresi (Song et al. 2017). $k$-NN menjadi salah satu metode terpopuler dan sederhana (Ke 2018), paling sukses pada teknik klasifikasi pola (Jiao, Pan, and Feng 2015). Menurut Neo dan Venture (Neo and Ventura 2012) $k$-NN efektif dalam pengenalan pola, memiliki konsep sederhana sehingga mudah diaplikasikan.

$k$-NN merupakan metode tertua dan paling sederhana dalam klasifikasi pola (Zolghadri, Parvinnia, and John 2009), akan tetapi $k$-NN memiliki kelemahan, yaitu hasil klasifikasi sangat dipengaruhi skala input data dan fungsi pengukuran jarak Euclidean memperlakukan atribut data secara sama, tidak sesuai dengan relevansi masing-masing atribut data yang berakibat pada menurunnya hasil klasifikasi (Zolghadri, Parvinnia, and John 2009). Kelemahan utama $k$-NN adalah hasilnya sangat dipengaruhi skala input data dan pengukuran atribut (Hocke and Martinetz 2015). $k$-NN memiliki dua kekurangan, 1) bergantung pada skala awal atribut dari data, 2) fungsi jarak Euclidean memperlakukan atribut data secara sama, kondisi ini tidak sesuai dengan kondisi data sebenarnya. Fungsi jarak Euclidean $k$-NN 
mengukur jarak tidak sesuai dengan relevansi masing-masing atribut data (Hocke and Martinetz 2013). Menurut Schenatto et al. (Schenatto et al. 2017) pengukuran kesamaan menggunakan fungsi jarak Euclidean sensitif terhadap rentang variabel masukan, umumnya variabel seperti ini dilakukan normalisasi.

Normalisasi merupakan tahap pre-processing yang sangat berguna untuk algoritma klasifikasi dengan cara mencegah perbedaan rentang yang besar antar atribut (Jiawei et al. 2012). Ada beberapa metode normalisasi yang dapat digunakan untuk normalisasi data (Jain, Nandakumar, and Ross 2005), salah satunya adalah metode MinMax. Metode MinMax merupakan metode normalisasi yang paling sederhana, di mana data baru diperoleh dengan cara data lama dikurangi data terkecil dan dibagi dengan data terbesar dikurangi data terkecil. Penerapan normalisasi data MinMax dapat meningkatkan kinerja algoritma Neural Network (NN) (Nawi, Atomi, and Rehman 2013), meningkatkan kinerja algoritma Artificial Neural Network (ANN) (Shabani et al. 2017) pada prediksi area daun.

Data hasil normalisasi kemudian diklasifikasi menggunakan metode k-NN dengan Euclidean distance sebagai fungsi pengukuran jaraknya. Menurut (Yunlong 2016) salah satu kelemahan Euclidean distance adalah memperlakukan atribut data secara sama, kondisi ini tidak sesuai dengan kondisi data sebenarnya. Menurut Siminski (Siminski 2017) setiap atribut belum tentu memiliki kontribusi yang sama terhadap kinerja algoritma, ada yang berkontribusi atau bahkan tidak memiliki kontribusi, dengan pembobotan atribut kinerja algoritma dapat ditingkatkan. Menurut Jiang et al. (Jiang et al. 2007) salah satu solusi untuk mengatasi permasalahan pada Euclidean distance ketika menghitung jarak antar data adalah dengan pembobotan atribut.

Pembobotan atribut dapat meningkatkan kinerja algoritma (Dialameh and Jahromi 2016) (Wu et al. 2015). Menurut Witten, Frank dan Hall (Witten, Frank, and Hall 2011) salah satu untuk meningkatkan kinerja $k$-NN adalah dengan pembobotan atribut. Ada beberapa metode pembobotan yang dapat digunakan untuk pembobotan atribut diantaranya adalah Information Gain, dan Gain Ratio (Da et al. 2012), Principal Component Analysis (PCA) (Cao and Liu 2010). Metode pembobotan atribut yang lain diantaranya coefficient of variation (CV) (Bechar and Vitner 2009), di mana nilai CV diperoleh dengan cara membagi nilai standard deviasi dengan nilai rata-rata atribut. Ren dan Fan (Ren and Fan 2011) berhasil meningkatkan kinerja algoritma $k$-means dengan metode pembobotan coefficient of variation.

Permasalahan pengukuran jarak pada algoritma $k$-NN telah menarik peneliti untuk melakukan perbaikan, diantaranya dengan melakukan pembobotan atribut, Large Margin Nearest Neighbor (LMNN) (Weinberger and Saul 2009), Weighted Distance Nearest Neighbor (WDNN) (Zolghadri, Parvinnia, and John 2009). Pada tahun 2011 Gou, Luo, dan Xiong mengusulkan Dual Distance Weighted Voting for $k$-Nearest Neighbor (DWKNN) (Gou, Luo, and Xiong 2011), hasil uji coba pada 10 dataset UCI Machine Learning Repository menunjukkan kinerja DWKNN lebih baik dari $k$-NN dan Distance Weighted $k$ Nearest Neighbor Rule (WKNN) (Dudani 1976). Akan tetapi menurut Mateos García, García Gutiérrez, dan Riquelme Santos (Mateos-García, García-Gutiérrez, and RiquelmeSantos 2017) DWKNN hanya fokus pada penentuan label dengan weight voting, tidak menggabungkan weight voting dengan seleksi atribut.

Dari uraian di atas dapat diperoleh informasi bahwa $k$-NN memiliki kelemahan sensitif terhadap skala input data, hal tersebut dapat diatasi dengan normalisasi data. Kelemahan lain $k$-NN terletak pada fungsi pengukuran jarak Euclidean distance yang memperlakukan atribut data secara sama tidak sesuai dengan relevansi masing-masing atribut data yang berakibat pada menurunnya hasil klasifikasi, kelemahan ini dapat diatasi dengan menambahkan bobot pada Euclidean distance yang dikenal dengan weighted Euclidean distance. 
Penelitian ini mengusulkan Coefficient of Variation Weighting k-Nearest Neighbor (CVWKNN) atau Algoritma $k$-Nearest Neighbor dengan Metode Pembobotan Koefisien Variasi, yaitu mengintegrasikan normalisasi MinMax untuk mengatasi kelemahan $k$-NN yang sensitif terhadap skala input data dengan weighted Euclidean distance untuk mengatasi Euclidean distance yang memperlakukan atribut data secara sama, di mana bobot atribut diperoleh dengan coefficient of variation (CV). Normalisasi MinMax dipilih karena sederhana, dapat mencegah rentang yang besar antar atribut, dan terbukti mampu meningkatkan kinerja algoritma Neural Network (NN) (Nawi, Atomi, and Rehman 2013), Artificial Neural Network (ANN) (Shabani et al. 2017). Weighted Euclidean distance dipilih karena penambahan bobot pada Euclidean distance mampu mengatasi Euclidean distance yang memperlakukan atribut data secara sama, dan sesuai dengan Jiang et al. (Jiang et al. 2007) bahwa pembobotan mampu mengatasi permasalahan pada Euclidean distance.

Paper ini disusun sebagai berikut, bagian 2 menjelaskan tinjauan pustaka. Pada bagian 3, menjelaskan metode penelitian. Hasil dan pembahasan disajikan pada bagian 4 . Kesimpulan dan saran disajikan pada bagian akhir.

\section{TINJAUAN PUSTAKA}

Permasalahan pengukuran jarak pada algoritma $k$-NN telah menarik peneliti untuk mengusulkan metode perbaikan. Pada tahun 2009 Zolghadri et al. mengusulkan Weighted Distance Nearest Neighbor (WDNN) (Zolghadri, Parvinnia, and John 2009). WDNN melakukan pembobotan pada data pelatihan, bobot diperoleh dengan menggunakan metode leave-one-out (LV1). Euclidean distance dimodifikasi mejadi weighted Euclidean distance untuk menghitung jarak data uji dengan data latih. Hasil uji coba pada 14 dataset publik menunjukkan kinerja rata-rata WDNN mengungguli Adaptive Nearest Neighbor (ANN) (Wang, Neskovic, and Cooper 2007) dan $k$-NN.

Pada tahun 2010 Yang, Cao, dan Zhang mengusulkan Weighted Distance $k$-Nearest Neighbor (WDKNN). Ini adalah pengembangan dari WDNN (Zolghadri, Parvinnia, and John 2009), jika WDNN memiliki kinerja bagus dengan nilai $k=1$ akan tetapi jika nilai $k>1$ kinerjanya menurun, maka pada WDKNN memiliki kinerja yang bagus meskipun nilai $k \geq$ 1. Hasil uji coba pada 20 dataset publik menunjukkan kinerja rata-rata WDKNN mengungguli WDNN dan $k$-NN.

Pada tahun 2011 Hu et al. (Hu et al. 2011) mengusulkan Sample Weight Learning via Minimizing Loss of Margin (SWL-MLM). Optimalisasi bobot data dilakukan dengan algoritma Gradient Decent. Untuk menghitung jarak data uji dengan data latih digunakan weighted Euclidean distance. Hasil uji coba pada 10 dataset publik menunjukkan kinerja rata-rata SWL-MLM lebih unggul dari Relief dan $k$-NN.

Pada tahun 2011 Gou, Luo, dan Xiong mengusulkan Dual Distance Weighted Voting for $k$-Nearest Neighbor (DWKNN). Metode ini merupakan pengembangan dari metode Distance Weighted $k$-NN (WKNN) (Dudani 1976). Meskipun hasil uji coba pada 10 dataset publik menunjukkan kinerja DWKNN lebih baik dari WKNN (Dudani 1976) dan $k$-NN akan tetapi DWKNN hanya fokus pada penentuan label dengan weight voting, tidak menggabungkan weight voting dengan seleksi atribut.

Penelitian ini mengusulkan integrasi normalisasi MinMax untuk mengatasi kelemahan $k$-NN yang sensitif terhadap skala input data dengan weighted Euclidean distance untuk mengatasi Euclidean distance yang memperlakukan atribut data secara sama, di mana bobot atribut diperoleh dengan coefficient of variation (CV).

\section{METODE PENELITIAN}

Penelitian ini mengusulkan Coefficient of Variation Weighting $k$-Nearest Neighbor $(\mathrm{CVWKNN})$, sebuah metode untuk mengatasi permasalahan pengukuran jarak pada 
algoritma $k$-NN dengan mengintegrasikan normalisasi MinMax dan weighted Euclidean distance. Kelemahan $k$-NN yang sensitif terhadap skala input data diatasi dengan normalisasi MinMax, sedangkan kelemahan Euclidean distance $k$-NN yang memperlakukan atribut data secara sama diatasi dengan weighted Euclidean distance.

Pada Gambar 1 ditampilkan alur kerja metode CVWKNN, sebagai berikut:

1. Memasukkan dataset atau himpunan data $\left(x_{i a}, y_{i}\right)$ di mana $i$ adalah urutan data $(1,2$, $\ldots, m), a$ adalah urutan atribut $(1,2, \ldots, n)$, dan $y$ adalah label;

2. Menentukan nilai $k$ tetangga terdekat;

3. Menghitung bobot atribut dengan coefficient of variation (CV);

4. Melakukan proses pengolahan data awal menggunakan normalisasi MinMax;

5. Menghitung jarak data uji dengan data latih dengan weighted Euclidean distance;

6. Mengurutkan hasil perhitungan jarak data uji dengan data latih dari urutan kecil ke besar;

7. Mengambil hasil perhitungan jarak yang sudah urut sesuai nilai $k$;

8. Menentukan hasil klasifikasi berdasarkan label mayoritas;

9. Menghitung akurasi hasil klasifikasi.

Secara umum metode CVWKNN sama dengan metode $k$-NN klasik, yang membedakan antara metode keduanya terletak pada tahap ke-3, ke-4, dan ke-5. Pada metode CVWKNN, tahap ke-3 terdapat proses penghitungan bobot atribut dengan coefficient of variation $(\mathrm{CV})$. Untuk menghitung bobot atribut ke- $a\left(w_{a}\right)$ digunakan Fungsi (1), di mana $a$ : atribut, $n$ : jumlah atribut, $c v_{a}$ : coefficient of variation atribut ke- $a$.

$$
w_{a}=\frac{c v_{a}}{\sum_{a=1}^{n} c v_{a}}
$$

Untuk menghitung coefficient of variation atribut ke- $a\left(c v_{a}\right)$ digunakan Fungsi (2), di mana $\delta_{a}$ : standar deviasi atribut ke- $a, \mu_{a}$ : nilai rata-rata atribut ke- $a$.

$$
c v_{a}=\frac{\delta_{a}}{\mu_{a}}
$$

Untuk menghitung standar deviasi atribut ke- $a\left(\delta_{a}\right)$ digunakan Fungsi (3) di mana $a$ : atribut, $m$ : jumlah data, $x_{i a}$ : data ke- $i$ atribut ke- $a, \mu_{a}$ : nilai rata-rata atribut ke- $a$.

$$
\delta_{a}=\sqrt{\frac{1}{m-1} \sum_{i=1}^{m}\left(x_{i a}-\mu_{a}\right)^{2}}
$$

Untuk menghitung nilai rata-rata atribut ke-a $\left(\mu_{a}\right)$ digunakan Fungsi (4) di mana a: atribut, $m$ : jumlah data, $x_{i a}$ : data ke- $i$ atribut ke- $a$.

$$
\mu_{a}=\frac{1}{m} \sum_{i=1}^{m} x_{i a}
$$

Pada metode CVWKNN, tahap ke-4 ditambahkan proses pengolahan data awal berupa normalisasi MinMax yang bertujuan menstandarkan nilai atribut pada skala tertentu sebelum dilakukan proses klasifikasi. Normalisasi MinMax telah digunakan oleh beberapa peneliti (Jain, Nandakumar, and Ross 2005) (Nawi, Atomi, and Rehman 2013) (Tzortzis and Likas 2014) (Venugopal and Sundaram 2017) untuk mengatasi permasalahan skala nilai atribut. Fungsi Normalisasi MinMax (5), di mana $z$ : nilai atribut hasil normalisasi, $x$ : nilai atribut, min $(x)$ : nilai minimal atribut, $\max (x)$ : nilai maksimal atribut.

$$
z=\frac{x-\min (x)}{\max (x)-\min (x)}
$$

Pada metode CVWKNN, tahap ke-5 hitung jarak data uji dengan data latih menggunakan weighted Euclidean distance. Jika pada $k$-NN klasik semua atribut dianggap sama, jarak antara data uji dengan data pelatihan dihitung dengan Euclidean distance (6) 
tanpa adanya pembobotan, di mana $d$ : distance, $x^{\prime}$ : data uji, $x$ : data latih, $a$ : atribut, $n$ : jumlah atribut.

$$
d\left(x^{\prime}, x\right)=\sqrt{\sum_{a=1}^{n}\left(x_{a}^{\prime}-x_{a}\right)^{2}}
$$

Maka pada metode CVWKNN, untuk mengukur jarak antara data uji dengan data pelatihan dihitung dengan weighted Euclidean distance (7), di mana $w$ adalah bobot yang diperoleh dengan fungsi (1).

$$
d\left(x^{\prime}, x\right)=\sqrt{\sum_{a=1}^{n} W^{2}\left(x^{\prime}{ }_{a}-x_{a}\right)^{2}}
$$

Label hasil klasifikasi diperoleh dari label mayoritas tetangga terdekatnya, sebagaimana Fungsi (8), di mana $y^{\prime}$ : label hasil klasifikasi, $y$ : label, $y_{i}$ : label ke- $i$ dari $k$ tetangga terdekatnya, $k$ : jumlah tetangga terdekat.

$$
y^{\prime}=\arg \max _{y} \sum_{i=1}^{k} y=y_{i}
$$

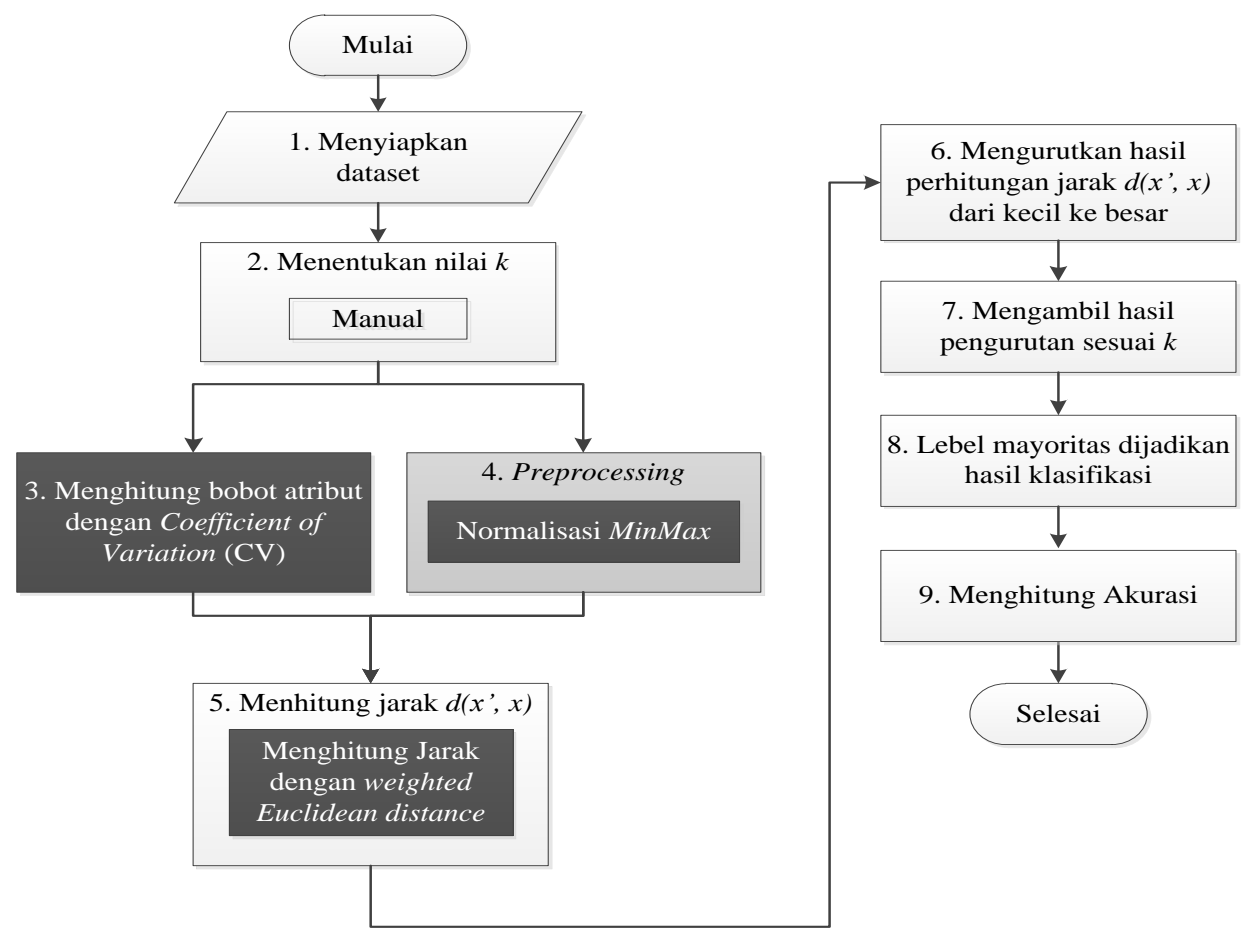

Gambar 1 Alur Kerja Metode CVWKNN

\section{HASIL DAN PEMBAHASAN}

Eksperimen dilakukan menggunakan komputer degan spesifikasi Intel Core i7-7500U 2,70 GHz, 8 GB RAM, sistem operasi Windows 10 Home 64-bit, serta aplikasi Rapid Miner Versi 7.5.

Tabel 1 Dataset yang Digunakan

\begin{tabular}{|c|l|c|c|c|}
\hline No & \multicolumn{1}{|c|}{ Nama Dataset } & Jumlah Data & Jumlah & Jumlah Label \\
\hline 1 & Wine & 178 & 13 & 3 \\
\hline 2 & Iris & 150 & 4 & 3 \\
\hline 3 & Balance Scale & 625 & 4 & 3 \\
\hline 4 & Heart & 270 & 13 & 2 \\
\hline 5 & Breast Cancer & 699 & 10 & 2 \\
\hline 6 & Ecoli & 336 & 8 & 7 \\
\hline 7 & Dermatology & 366 & 34 & 6 \\
\hline
\end{tabular}


Pada Tabel 1 ditampilkan 7 dataset dari UCI Machine Learning Repository yang digunakan dalam eksperimen ini. Semua dataset bertipe numerik dengan jumlah data mulai dari 150 sampai dengan 699, jumlah atribut mulai dari 4 sampai dengan 34, serta label bertipe binominal dan polynominal.

Split data digunakan untuk membagi dataset menjadi data uji dan data pelatihan dengan perbandingan 20:80. Evaluasi hasil eksperimen menggunakan akurasi. Akurasi menggambarkan persentase data uji yang diklasifikasikan benar oleh metode klasifikasi (Jiawei et al. 2012). Friedman test dan Nemenyi post hoc test digunakan untuk mengetahui perbedaan yang signifikan antar metode yang diperbandingkan. Menurut Demsar (Demsar 2006), Friedman test sesuai digunakan untuk perbandingan pada lebih dari dua metode pada beberapa dataset.

Untuk mengetahui kinerja metode usulan, CVWKNN dibandingkan dengan $k$-NN, MinMax $k$ NN, dan DWKNN. Seluruh metode yang diperbandingkan diuji dengan nilai $k=5$, kemudian dapat dilihat metode mana yang memiliki kinerja terbaik. Pada Tabel 2, Gambar 2, dan Gambar 3 ditampilkan perbandingan akurasi metode yang diperbandingkan, dan dapat dilihat bahwa CVWKNN memiliki akurasi rata-rata tertinggi.

Tabel 2 Perbandingan Akurasi pada Tujuh Dataset dari Metode yang Diperbandingkan

\begin{tabular}{|l|l|l|l|l|}
\hline \multicolumn{1}{|c|}{ Dataset } & $\begin{array}{c}\text { Akurasi } \\
\boldsymbol{k} \text {-NN }\end{array}$ & $\begin{array}{c}\text { Akurasi } \\
\text { MinMax } \boldsymbol{k} \text {-NN }\end{array}$ & $\begin{array}{c}\text { Akurasi } \\
\text { DWKNN }\end{array}$ & $\begin{array}{c}\text { Akurasi } \\
\text { CVWKNN }\end{array}$ \\
\hline Wine & $77.78 \%$ & $91.67 \%$ & $83.33 \%$ & $\mathbf{9 7 . 2 2 \%}$ \\
\hline Iris & $80.00 \%$ & $83.33 \%$ & $80.00 \%$ & $\mathbf{9 0 . 0 0 \%}$ \\
\hline Balance Scale & $80.16 \%$ & $\mathbf{8 3 . 3 3 \%}$ & $80.16 \%$ & $82.54 \%$ \\
\hline Heart & $62.96 \%$ & $\mathbf{7 9 . 6 3 \%}$ & $68.52 \%$ & $75.93 \%$ \\
\hline Breast Cancer & $\mathbf{9 5 . 7 1 \%}$ & $\mathbf{9 5 . 7 1 \%}$ & $93.57 \%$ & $\mathbf{9 5 . 7 1 \%}$ \\
\hline Ecoli & $87.88 \%$ & $87.88 \%$ & $78.79 \%$ & $\mathbf{8 9 . 3 9 \%}$ \\
\hline Dermatology & $87.50 \%$ & $87.50 \%$ & $90.28 \%$ & $\mathbf{9 7 . 2 2 \%}$ \\
\hline Akurasi rata-rata & $81.71 \%$ & $87.01 \%$ & $82.09 \%$ & $\mathbf{8 9 . 7 2 \%}$ \\
\hline
\end{tabular}

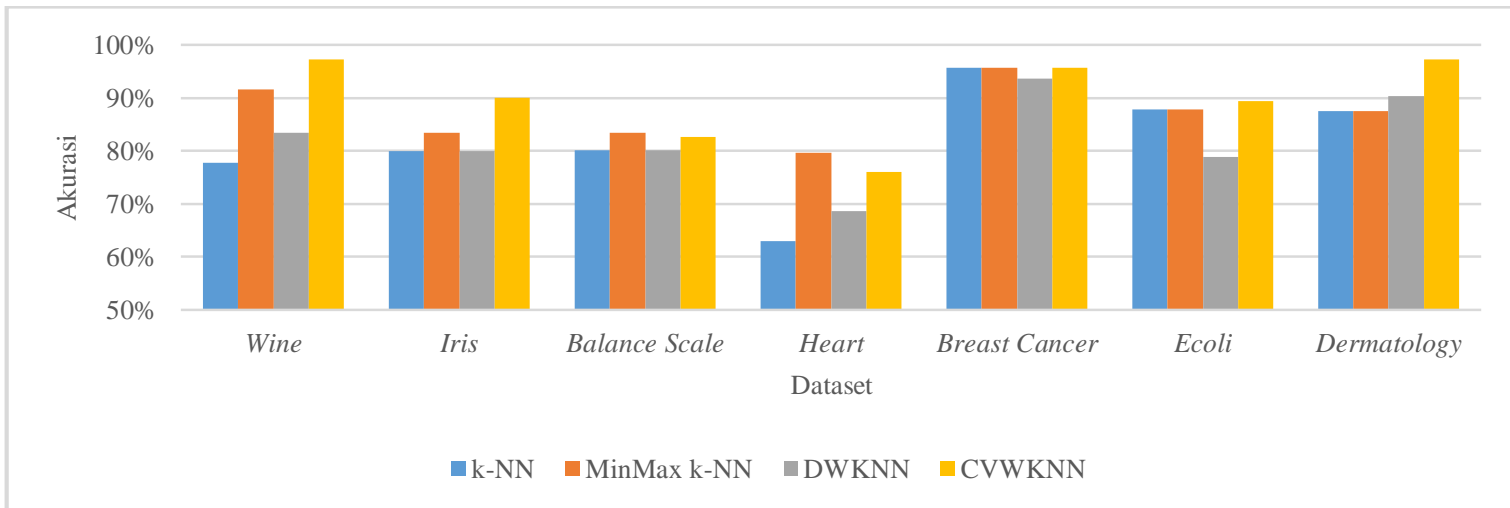

Gambar 2 Grafik Perbandingan Akurasi pada Tujuh Dataset dari Metode yang Diperbandingkan

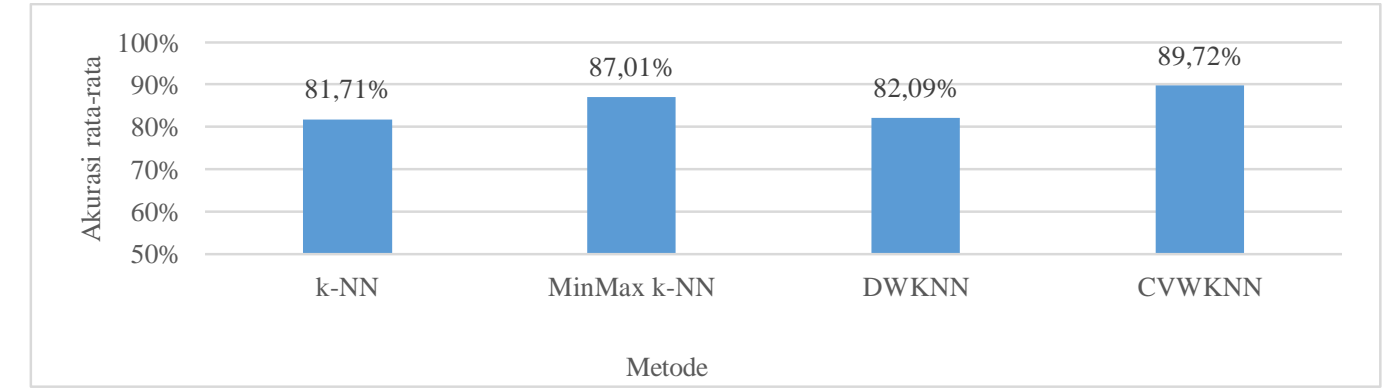

Gambar 3 Grafik Perbandingan Akurasi Rata-Rata pada Tujuh Dataset dari Metode yang Diperbandingkan 
Pada tahap akhir, untuk mengetahui perbedaan yang signifikan antar metode yang diperbandingkan dilakukan Friedman test dan Nemenyi post hoc test. Friedman test membandingkan peringkat rata-rata kinerja atau average ranked $(\mathrm{R})$ metode pada setiap dataset (Wahono, Herman, and Ahmad 2014). Pada Friedman test taraf pengujian $(\alpha)$ ditentukan sebesar 5\% atau 0.05. Hipotesis, H0: tidak terdapat perbedaan nilai rata-rata antar metode yang diperbandingkan, Ha: terdapat perbedaan nilai rata-rata antar metode yang diperbandingkan. Daerah penolakan, tolak H0 jika $P$-value lebih kecil daripada $\alpha$ (alpha) dan Ha diterima. Terima H0 jika $P$-value lebih besar daripada $\alpha$ (alpha) dan Ha ditolak. Setelah Friedman test dilakukan jika hasilnya $\mathrm{H} 0$ ditolak dan $\mathrm{Ha}$ diterima, selanjutnya dilakukan Nemenyi post hoc test.

Nemenyi post hoc test digunakan untuk membandingkan satu sama lain diantara semua metode klasifikasi yang diperbandingkan. Kinerja dua metode klasifikasi dikatakan berbeda signifikan jika hasil perbandingan peringkat rata-rata kinerja lebih besar dari nilai Critical Different (CD). Fungsi yang digunakan ditampilkan pada Fungsi (9), di mana $C D$ : Critical Different, $q_{a}$ : student sized range statistic, $K$ : jumlah metode yang diperbandingkan, $D$ : jumlah dataset. Pada Tabel 3 ditampilkan nilai $q_{a}$ pada $\alpha$ (alpha) 0.05 (Demsar 2006). Jadi nilai $q_{a}$ sesuai jumlah metode yang diperbandingkan.

$$
C D=q_{a} \sqrt{\frac{K(K+1)}{6 D}}
$$

Tabel 3 Nilai $q_{a}$ Pada $\alpha=0.05$

\begin{tabular}{|c|c|c|c|c|c|c|c|c|c|}
\hline Metode & 2 & 3 & 4 & 5 & 6 & 7 & 8 & 9 & 10 \\
\hline$q_{a} .05$ & 1.960 & 2.343 & 2.569 & 2.728 & 2.850 & 2.949 & 3.031 & 3.102 & 3.164 \\
\hline
\end{tabular}

\section{Pada}

Tabel 4 ditampilkan hasil Friedman test akurasi metode yang diperbandingkan, di mana nilai $\boldsymbol{p}=\mathbf{0 . 0 1}$ lebih kecil dari alpha $(\alpha=0.05)$ maka $\mathrm{H} 0$ ditolak dan Ha diterima, sehingga dapat disimpulkan terdapat perbedaan yang signifikan antar metode yang diperbandingkan. Pada

Tabel 5 ditampilkan perbandingan berpasangan Nemenyi post hoc test akurasi metode yang diperbandingkan dibandingkan dengan nilai CD. Metode CVWKNN dibandingkan dengan $k$-NN memperoleh nilai $\mathbf{1 . 8 6}$ dan dibandingkan dengan DWKNN memperoleh nilai 1.86 lebih besar dari nilai Critical Different $(\mathrm{CD})=\mathbf{1 . 7 7}$, sedangkan dibandingkan dengan MinMax $k$-NN memperoleh nilai 0.57 lebih kecil dari nilai Critical Different $(\mathrm{CD})=\mathbf{1 . 7 7}$. Pada Tabel 6 ditampilkan perbedaan signifikan pada Nemenyi post hoc test dari akurasi metode yang diperbandingkan. Dilihat dari akurasi, CVWKNN memiliki perbedaan kinerja yang signifikan jika dibandingkan $k$-NN dan DWKNN, sedangkan dibandingkan dengan MinMax $k$-NN, CVWKNN tidak berbeda secara signifikan.

Tabel 4 Hasil Friedman Test Akurasi Metode yang Diperbandingkan

\begin{tabular}{|l|r|}
\hline $\mathrm{Q}$ (Observed value) & 12.48 \\
\hline $\mathrm{Q}$ (Critical value) & 7.81 \\
\hline $\mathrm{DF}$ & 3 \\
\hline$p$-value $($ Two-tailed $)$ & 0.01 \\
\hline alpha & 0.05 \\
\hline
\end{tabular}


Tabel 5 Perbandingan Berpasangan Nemenyi Post Hoc Test dari Akurasi Dibandingkan dengan Critical Different

\begin{tabular}{|l|l|l|l|l|}
\hline \multicolumn{1}{|c|}{ Metode } & \multicolumn{1}{c|}{$\boldsymbol{k}$-NN } & \multicolumn{1}{c|}{ MinMax $\boldsymbol{k}$-NN } & \multicolumn{1}{c|}{ DWKNN } & \multicolumn{1}{c|}{ CVWKNN } \\
\hline$k$-NN & 0.00 & -1.29 & 0.00 & $\mathbf{- 1 . 8 6}$ \\
\hline MinMax $k$-NN & 1.29 & 0.00 & 1.29 & -0.57 \\
\hline DWKNN & 0.00 & -1.29 & 0.00 & $\mathbf{- 1 . 8 6}$ \\
\hline CVWKNN & $\mathbf{1 . 8 6}$ & 0.57 & $\mathbf{1 . 8 6}$ & 0.00 \\
\hline Critical Different & $\mathbf{1 . 7 7}$ & \multicolumn{4}{|l}{} \\
\hline
\end{tabular}

Tabel 6 Perbedaan Signifikan pada Nemenyi Post Hoc Test dari Akurasi Metode yang Diperbandingkan

\begin{tabular}{|l|l|l|l|l|}
\hline \multicolumn{1}{|c|}{ Metode } & \multicolumn{1}{c|}{$\boldsymbol{k}$-NN } & \multicolumn{1}{c|}{ MinMax $\boldsymbol{k}$-NN } & \multicolumn{1}{c|}{ DWKNN } & \multicolumn{1}{c|}{ CVWKNN } \\
\hline$k$-NN & No & No & No & Yes \\
\hline MinMax $k$-NN & No & No & No & No \\
\hline DWKNN & No & No & No & Yes \\
\hline CVWKNN & Yes & No & Yes & No \\
\hline
\end{tabular}

\section{KESIMPULAN DAN SARAN}

\subsection{Kesimpulan}

CVWKNN, integrasi normalisasi MinMax dan weighted Euclidean distance diusulkan untuk meningkatkan kinerja algoritma $k$-NN. Normalisasi MinMax dimanfaatkan untuk mengatasi skala input data, sedangkan weighted Euclidean distance digunakan untuk mengatasi Euclidean distance yang memperlakukan atribut data secara sama, tidak sesuai dengan relevansi masing-masing atribut data. CVWKNN diujicobakan pada 7 dataset publik dari UCI Machine Learning Repository. Hasil uji coba menunjukkan kinerja metode usulan lebih baik dari $k$-NN. Kesimpulan penelitian ini adalah metode usulan mampu mengatasi kelemahan pada algoritma $k$-NN, sehingga kinerja algoritma $k$-NN meningkat.

\subsection{Saran}

Saran untuk penelitian selanjutnya Pada penelitian ini nilai $k$ ditentukan secara manual, pada penelitian selanjutnya nilai $k$ dapat ditentukan secara otomatis. Pada penelitian ini untuk menghitung bobot atribut mengagunkan coefficient of variation (CV), pada penelitian selanjutnya dapat digunakan metode pembobotan yang lain seperti deep feature weighting untuk meningkatkan kinerja algoritma k-NN.

\section{DAFTAR PUSTAKA}

Akhil, M, B L Deekshatulu, and Priti Chandra. 2013. "Classification of Heart Disease Using K- Nearest Neighbor and Genetic Algorithm.” In Procedia Technology, 10:85-94. Kalyani, Nadia, West Bengal, September 27-28: Elsevier B.V.

Bechar, Avital, and Gad Vitner. 2009. "A Weight Coefficient of Variation Based Mathematical Model to Support the Production of ' Packages Labelled by Count' in 
Agriculture." Biosystems Engineering $104 \quad$ (3). IAgrE: 362-68. doi:10.1016/j.biosystemseng.2009.08.003.

Cao, Qinghua, and Yu Liu. 2010. "A KNN Classifier with PSO Feature Weight Learning Ensemble." In International Conference on Intelligent Control and Information Processing, 110-14. Dalian, Aug 13-15.

Christian Gratia Nugroho, Didik Nugroho, Sri Hariyati Fitriasih. 2015. "Sistem Pendukung Keputusan Untuk Pemilihan Metode Kontrasepsi PADA Pasangan Usia Subur Dengan Algoritna K-Nearset Neighbor (K-KN)." Jurnal Ilmiah SINUS 13 (1): 21-30. doi:10.2473/shigentosozai1953.83.947_421.

Da, H, K E Say, I Yenido, S Albayrak, and C Acar. 2012. "Comparison of Feature Selection Algorithms for Medical Data." In 2012 International Symposium on Innovations in Intelligent Systems and Applications. Trabzon, July 2-4.

Demsar, Janez. 2006. "Statistical Comparisons of Classifiers over Multiple Data Sets." Journal of Machine Learning Research 7 7: 1-30.

Dialameh, Maryam, and Mansoor Zolghadri Jahromi. 2016. "Proposing a General Feature Weighting Function." Expert Systems With Applications. Elsevier Ltd. doi:10.1016/j.eswa.2016.12.016.

Dudani, Sahibsingh A. 1976. "The Distance-Weighted K-Nearest-Neighbor Rule." IEEE Transactions on Systems, Man and Cybernetics SMC-6 (4): 325-27. doi:10.1109/TSMC.1976.5408784.

Gou, Jianping, Mingying Luo, and Taisong Xiong. 2011. "Improving K-Nearest Neighbor Rule with Dual Weighted Voting for Pattern Classification." Communications in Computer and Information Science 159 CCIS (PART 2): 118-23. doi:10.1007/978-3642-22691-5_21.

Han, Jiawei, and Micheline Kamber. 2011. Data Mining: Concepts and Techniques. Elsevier. Second Edi. Vol. 12. Elsevier Inc. doi:10.1007/978-3-642-19721-5.

Hocke, Jens, and Thomas Martinetz. 2013. "Feature Weighting by Maximum Distance Minimization." In International Conference on Artificial Neural Networks, 420-25. Bulgaria, September 10-13.

—. 2015. "Maximum Distance Minimization for Feature Weighting." Pattern Recognition Letters 52. Elsevier Ltd.: 48-52. doi:10.1016/j.patrec.2014.10.003.

$\mathrm{Hu}$, Qinghua, Pengfei Zhu, Yongbin Yang, and Daren Yu. 2011. "Large-Margin Nearest Neighbor Classifiers via Sample Weight Learning." Neurocomputing 74 (4). Elsevier: 656-60. doi:10.1016/j.neucom.2010.09.006.

Jain, Anil, Karthik Nandakumar, and Arun Ross. 2005. "Score Normalization in Multimodal Biometric Systems." Pattern Recognition 38: 2270-85. doi:10.1016/j.patcog.2005.01.012.

Jiang, Liangxiao, Zhihua Cai, Dianhong Wang, and Siwei Jiang. 2007. "Survey of Improving K-Nearest-Neighbor for Classification." In Proceedings - Fourth International Conference on Fuzzy Systems and Knowledge Discovery, FSKD 2007, 1:679-83. Haikou, Aug 24-27. doi:10.1109/FSKD.2007.552.

Jiao, Lianmeng, Quan Pan, and Xiaoxue Feng. 2015. "Multi-Hypothesis Nearest-Neighbor Classifier Based on Class-Conditional Weighted Distance Metric." Neurocomputing 151 (P3). Elsevier: 1468-76. doi:10.1016/j.neucom.2014.10.039.

Jiawei, H, Micheline Kamber, Jiawei Han, Micheline Kamber, and Jian Pei. 2012. Data Mining: Concepts and Techniques. San Francisco, CA, Itd: Morgan Kaufmann. Third Edit. Elsevier Inc. doi:10.1016/B978-0-12-381479-1.00001-0.

Ke, N. 2018. "Region Based Segmentation of Social Images Usinng Soft KNN Algorithhm." In Procedia Computer Science, 125:93-98. Kurukshetra, December 7-8: Elsevier B.V. doi:10.1016/j.procs.2017.12.014. 
Mateos-García, Daniel, Jorge García-Gutiérrez, and José C. Riquelme-Santos. 2017. “On the Evolutionary Weighting of Neighbours and Features in the K-Nearest Neighbour Rule." Neurocomputing 0: 1-7. doi:10.1016/j.neucom.2016.08.159.

Nawi, Nazri Mohd, Walid Hasen Atomi, and M Z Rehman. 2013. "The Effect of Data PreProcessing on Optimized Training of Artificial Neural Networks." In Procedia Technology, 11:32-39. Selangor, Jun 24-25: Elsevier B.V. doi:10.1016/j.protcy.2013.12.159.

Neo, Toh Koon Charlie, and Dan Ventura. 2012. "A Direct Boosting Algorithm for the KNearest Neighbor Classifier via Local Warping of the Distance Metric." Pattern Recognition Letters 33 (1). Elsevier B.V.: 92-102. doi:10.1016/j.patrec.2011.09.028.

Raymundus, Nandy Irawan;, Wawan Laksito; YS, and Sri Siswanti. 2013. "ISSN : 16931173 Sistem Pendukung Keputusan Untuk Menentukan Status Prestasi Siswa Menggunakan Metode K- Nearest Neighbor Raymundus Nandy Irawan, Wawan Laksito YS., Sri Siswanti." Jurnal Ilmiah SINUS 11 (2): 53-66.

Ren, Shuhua, and Alin Fan. 2011. "K -Means Clustering Algorithm Based On Coefficient Of Variation." In 2011 4th International Congress on Image and Signal Processing, 2076-79. Shanghai, October 15-17.

Schenatto, Kelyn, Eduardo Godoy De Souza, Claudio Leones Bazzi, Alan Gavioli, Nelson Miguel, and Humberto Martins. 2017. "Normalization of Data for Delineating Management Zones." Computers and Electronics in Agriculture 143 (November). Elsevier: 238-48. doi:10.1016/j.compag.2017.10.017.

Shabani, Ali, Keramat Allah, Ali Reza, and Ali Akbar Kamgar-haghighi. 2017. "Using the Artificial Neural Network to Estimate Leaf Area." Scientia Horticulturae 216. Elsevier B.V.: 103-10. doi:10.1016/j.scienta.2016.12.032.

Siminski, Krzysztof. 2017. "Fuzzy Weighted C-Ordered Means Clustering Algorithm." Fuzzy Sets and Systems 1. Elsevier B.V.: 1-33. doi:10.1016/j.fss.2017.01.001.

Song, Yunsheng, Jiye Liang, Jing Lu, and Xingwang Zhao. 2017. "An Efficient Instance Selection Algorithm for K Nearest Neighbor Regression.” Neurocomputing. Elsevier B.V. doi:10.1016/j.neucom.2017.04.018.

Tzortzis, Grigorios, and Aristidis Likas. 2014. "The MinMax K -Means Clustering Algorithm." Pattern Recognition 47 (7). Elsevier: 2505-16. doi:10.1016/j.patcog.2014.01.015.

Venugopal, Vivek, and Suresh Sundaram. 2017. "An Online Writer Identification System Using Regression-Based Feature Normalization and Codebook Descriptors." Expert Systems With Applications 72. Elsevier Ltd: 196-206. doi:10.1016/j.eswa.2016.11.038.

Wahono, Romi Satria, Nanna Suryana Herman, and Sabrina Ahmad. 2014. "A Comparison Framework of Classification Models for Software Defect Prediction." Advanced Science Letters 20 (10-12): 1945-50. doi:10.1166/asl.2014.5640.

Wang, Jigang, Predrag Neskovic, and Leon N. Cooper. 2007. "Improving Nearest Neighbor Rule with a Simple Adaptive Distance Measure.” Pattern Recognition Letters 28 (2): 207-13. doi:10.1016/j.patrec.2006.07.002.

Weinberger, Kilian Q, and Lawrence K Saul. 2009. "Distance Metric Learning for Large Margin Nearest Neighbor Classification." The Journal of Machine Learning Research 10: 207-44. doi:10.1126/science.277.5323.215.

Witten, Ian, Eibe Frank, and Mark Hall. 2011. Data Mining Practical Machine Learning Tools and Techniques Third Edition. Data Mining. Vol. 277. Elsevier Inc. doi:10.1002/1521-3773(20010316)40:6<9823::AID-ANIE9823>3.3.CO;2-C.

Wu, Jia, Shirui Pan, Xingquan Zhu, Zhihua Cai, Peng Zhang, and Chengqi Zhang. 2015. "Self-Adaptive Attribute Weighting for Naive Bayes Classification." Expert Systems with Applications 42 (3). Elsevier Ltd: 1487-1502. doi:10.1016/j.eswa.2014.09.019. 
Yunlong, GAO; Yixiao LIU. 2016. “An Improved Feature-Weight Method Based on KNN.” In Proceedings of the 35th Chinese Control Conference, 6950-56. Chengdu, July 27-29.

Zolghadri, Mansoor, Elham Parvinnia, and Robert John. 2009. "A Method of Learning Weighted Similarity Function to Improve the Performance of Nearest Neighbor." Information Sciences 179 (17). Elsevier Inc.: 2964-73. doi:10.1016/j.ins.2009.04.012. 